\title{
Relating mechanisms of higher education and research closely to the reality in the society for rural transformation in the Amhara region, Ethiopia
}

\author{
Getachew Alemayehu ${ }^{1 *}$, Sisay Yehuala ${ }^{2}$, Yonas Worku ${ }^{3}$, Zerihun Nigussie ${ }^{4}$, \\ Girmachew Seraw ${ }^{4}$ \\ ${ }^{1}$ Department of Plant Science, College of Agriculture and Environmental Science, Bahir-Dar University, Bahir Dar, Ethiopia; \\ *Corresponding Author: getachew.64@gmail.com \\ ${ }^{2}$ Department of Rural Development and Agricultural Extension, Faculty of Agriculture, Gondar University, Gondar, Ethiopia \\ ${ }^{3}$ North Gondar Research Centre, Amhara Region Agricultural Research Institute, Gondar, Ethiopia \\ ${ }^{4}$ Department of Rural Development, College of Agriculture and Environmental Science, Bahir Dar University, Bahir Dar, Ethiopia
}

Received 27 March 2012; revised 11 May 2012; accepted 23 August 2012

\section{ABSTRACT}

Higher education and research in Ethiopia is going through a decisive phase of reform and expansion. As a system it is increasingly required to respond and gear adequately to the development needs of the society and the country. This change is taking place through a government-led radical review of the system's status and challenges, and by devising mechanisms of consensus building, as well as ownership and overcoming the resistance to change. Higher education and research institutions of Bahir Dar and Gondar Universities and ARARI, in Ethiopia are not satisfactorily responsive to rural transformation in addressing problems of small-scale farmers. This calls for responsive education and research that addresses farmers' constraints. Thus, to survey the suitabilitylappropriateness of the current training programmes of higher education and research institutions to address the actual problems of farmers is of paramount importance. To this effect, tools such as interview guide, check-list and questionnaires were put to use for data collection. Primary data was collected from observation, focus group discussions and key informant interviews. Descriptive statistics for quantitative data and triangulation for qualitative data were the prime techniques for data analysis. The result of the study shows that university heads, instructors, students, research heads, researchers and employees rated the suggested mechanisms, namely "inviting speakers from industries and farming community", "visiting guest lecturers" and "special entrepreneurial project", as the top most important for ensuring training and research closely to the reality in the society of Amhara region in facilitating agricultural growth and rural transformation. Besides, employers and farmers responded that fresh graduates are deficient with relevant technical skills because of less emphasis on experiential learning on higher education. Therefore, the curriculum for the training should give much weight to incorporate these suggested mechanisms and the higher institutions curriculum should be arranged in such a way that the trainees could obtain appropriate technical knowhow.

Keywords: Relating Mechanism; Rural Transformation; Education; Research

\section{INTRODUCTION}

Higher education and research is of paramount importance for economic and social development. Inculcating relevant knowledge and advanced skills, higher education provides the human resources required for leadership, management, business and professional positions. The institutions also serve as the major research establishments that generate, adopt and disseminate knowledge. By giving people access to knowledge and the tools for increasing and diversifying their knowledge, higher education and research expands people's productivity, as well as national capacity and competitiveness. Today, as the world becomes increasingly interconnected, more interdependent and increasingly a globalized village, higher education and research is critical for the 
achievement of economic progress, political stability and peace, as well as for building democratic culture and society [1].

The 20th century's scientific and technological achievements were due, in large part, to the growth of higher education and the immense contribution and endeavor of the personnel trained within it. Without adequate higher education and research institutions providing a critical mass of skilled and educated people, no country can ensure genuine endogenous and sustainable development [2].

Higher education and research in Ethiopia is going through a decisive phase of reform and expansion. As a system it is increasingly required to respond and gear adequately to the development needs of the society and the country. This change is taking place through a government-led radical review of the system's status and challenges, and by devising mechanisms of consensus building, as well as ownership and overcoming the resistance to change [3].

A multidimensional crisis of profound economic impact and social deterioration during the Derg regime (1974-1991) contributed to weaken institutions of higher education and research in Ethiopia. It has undermined the confidence, which socio-economic patterns had in them and diminished their quality, efficiency and impact on development. Until about a decade ago, the absence of a clear vision of the social and economic importance of higher education and research, severe resource constraints and settings that provide access to the benefit of the elite only have contributed to the fact that the contribution of higher education and research to socioeconomic development in Ethiopia has been much less than expected. Therefore, there was a need to revitalize and transform the sector immediately after the downfall of the Derg regime [4].

Higher education and research institutions of Bahir Dar and Gondar Universities and ARARI, in Ethiopia are not satisfactorily responsive to rural transformation in addressing problems of small-scale farmers. This calls for responsive education and research that addresses farmers' constraints.

This study area, Amhara National Regional State (ANRS), is one of the states of the Federal Democratic Republic of Ethiopia. The ANRS is located in the Northwestern part of Ethiopia between 8045' and 13,045' North latitude and 35,045' and 40,025' East longitudes. The boundaries of the ANRS adjoin Tigray in the North, Oromia in the South, Afar in the East, Benishangul Gumuz in the South West, and Sudan in the North West. The State is divided into 11 administrative zones, including the capital city of the region, Bahir Dar. The other 10 Administrative Zones are: East Gojam, West Gojam, Awi, North Gonder, South Gonder, Wag Himra, North Wollo,
South Wollo, North Shewa, and Oromia [5]. The region is consists of 101 districts and 5300 rural and urban kebeles [6].

The total area of the region is $170,752 \mathrm{~km}^{2}$. Topography is divided mainly into plains, mountains, valleys, and undulating lands. The high and mid-altitude areas (about 65\% of total areas) are characterized by a chain of mountains and a central plateau. The lowland part, constituting 33\% of the total area, covers the Western and Eastern parts of the region; these are mainly plains that are large river drainage basins. Of the total area of the region, $27.3 \%$ is under cultivation, $30 \%$ is under grazing and browsing, $14.7 \%$ is covered by forest, bush, and herbs, and $18.9 \%$ is currently not used for productive purposes. The remaining 9.1\% represent settlement sites, swampy areas, and lakes [6].

The population of the region was estimated to be 17.7 million in 2003. Of these, 90.3\% live in rural areas. Mean population density is 91 persons $/ \mathrm{km}^{2}$ and ranges between 39 persons $/ \mathrm{km}^{2}$ in Wag Himra to 151 persons/ $\mathrm{km}^{2}$ in West Gojam [5]. Persons below 25 years of age form more than $65 \%$ of the population. A large proportion of the population in ANRS depends up on crop and livestock farming. Cropping systems are predominantly rain-fed. Because of population pressure and poor land husbandry, the level of land degradation and environmental depletion is worsening over time [7].

\section{Objectives of the Study}

The objective of the study was therefore: To survey the suitability/appropriateness of the current training programmes of higher education and research institutions to address the actual problems of farmers.

\section{RESEARCH METHODS}

\subsection{Data Sources and Collection}

The study was empirically grounded to get background of higher education and research institutions of Amhara region/Ethiopia corresponding to their responsiveness to rural transformation. Tools such as interview guide, check-list and questionnaires were put to use for data collection. Primary data was collected from observation, focus group discussions and key informant interviews. Higher education institutions (Bahir Dar University and Gondar University); Research institutions (ARARI head quarter and Gondar Research Centre); Employing organizations (Extension and related offices, District and village cabinets, NGOs and Privates) and farmers in Amarah region, which were identified and segregated for focus group discussions and key informant interviews, were the prime source of data.

The survey was undertaken at Bahir Dar and Gondar 


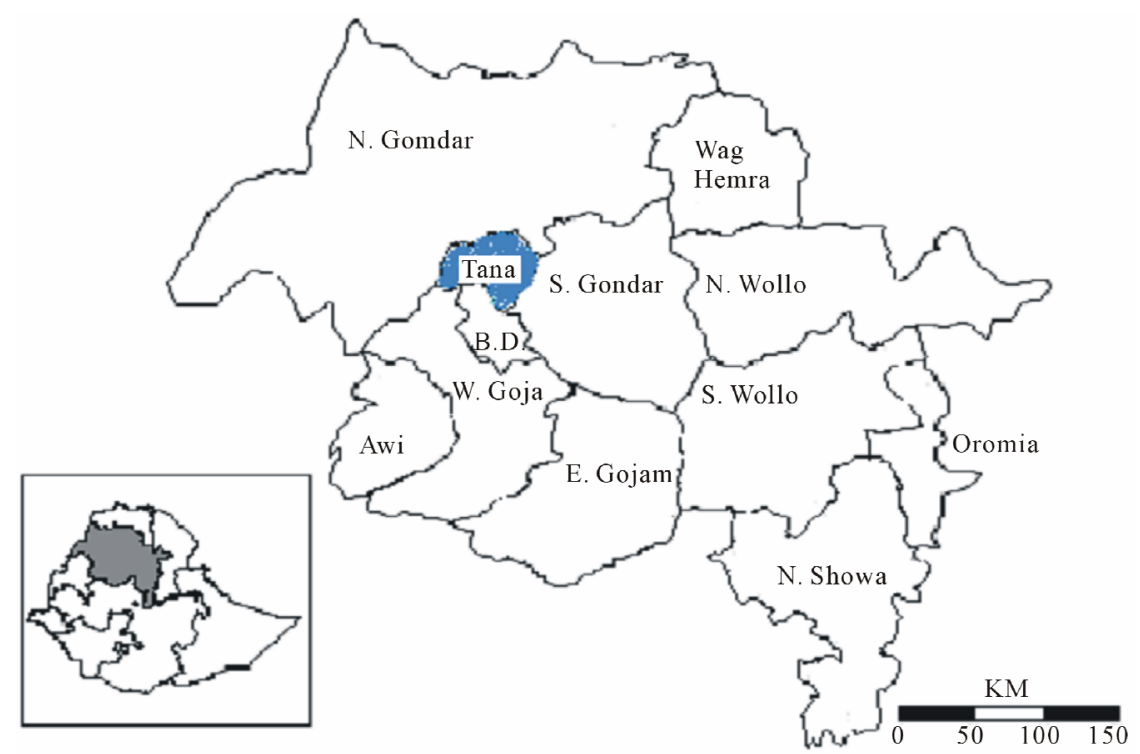

Figure 1. Location of ANRS in Ethiopia. Source: UNDP-1996.

Universities of Amhara region selected on purposeful sampling. Heads of the Agriculture faculties and departments of universities were taken as respondents. Instructors and students of the agricultural departments were randomly interviewed. Research directors and researchers of ARARI at head quarter office and Gondar Agricultural Research Centre Branch were purposively used for the study.

Three Woredas were selected for district level survey studies, where the three selected watersheds of the project were found. All development agents (DAs) working in the three selected watersheds were used for the study. The researchers used list of households from office of development agents and district agriculture and rural development office to select farmers randomly in the selected watersheds.

\subsection{Data Analysis}

The data obtained from the questionnaires interview were summarized, ranked and expressed using simple descriptive statistics. Attention was given for the qualitative data obtained from the observations, focus group discussion and key informant interview. Counting \& comparing, looking for patterns, commonalities and oddities; trend and seasonality analysis, prioritising, segmenting and classifying were the prime techniques of data analysis for the qualitative data.

\section{RESULTS AND DISCUSSION}

Relating mechanisms of higher education and research closely to the reality in the society for rural transformation in the Amhara region, Ethiopia.

Eight suggested mechanisms, which may ensure edu- cation and research activities closely related to the reality in the society, were assessed by university heads, instructors, students, research heads, researchers and employees (alumni). The majority of university heads (81.3\%) agreed with the importance of all suggested mechanisms in linking education and research closely to the reality in the society (Table 1). Respondent university heads ranked "inviting speakers from industries and farming community" first and "visiting guest lecturers" and "special entrepreneurial project" second most important linkage mechanisms (Table 1). Exceptionally, "involvement of stakeholders in curriculum development" was rated by university heads least with a mean value of 2.50 .

Instructor respondents also supported the suggested mechanisms to ensure training and research as closely as to the reality in the society (Table 2). Although their response mean values were not as high as that of university heads, similar to university heads, instructors rated "inviting speakers from industries and farming community" and "visiting guest lecturers" as the first and second most important liking mechanisms of training and research to the rural conditions (Table 2). Responses of instructors were deviated from that of university heads on "field trips/visits", "experiential leaning”, "students' practical attachment" and "special entrepreneurial project".

With different ranking orders, "inviting speakers from industries and farming community", "visiting guest lecturers" and "special entrepreneurial project" were rated by both research heads and researchers as the most top three mechanisms ensuring training and research closely to the reality of small-scale farmers (Tables 3 and 4). Both research heads and researchers similarly ranked "experience sharing" at fourth place. But, research heads 
Table 1. Mechanisms ensuring training and research closely to the reality in the society as rated by heads of higher education institutions.

\begin{tabular}{|c|c|c|c|c|c|c|c|}
\hline \multirow{2}{*}{ Mechanism } & \multicolumn{5}{|c|}{ Rating (frequency) } & \multirow{2}{*}{ Mean } & \multirow{2}{*}{ Rank } \\
\hline & Never 1 & Rarely 2 & Often 3 & Very often 4 & Always 5 & & \\
\hline Field trips/visits & 0 & 1 & 7 & 9 & 1 & 3.56 & 3 \\
\hline Experiential learning & 1 & 2 & 3 & 11 & 1 & 3.50 & 4 \\
\hline Visiting guest lecturers & 0 & 2 & 1 & 8 & 7 & 4.11 & 2 \\
\hline Student practical attachment & 3 & 1 & 4 & 5 & 5 & 3.44 & 5 \\
\hline Invited speakers from industries and farming community & 0 & 2 & 1 & 6 & 9 & 4.22 & 1 \\
\hline Involvement of stakeholders in curriculum development & 4 & 4 & 7 & 3 & 0 & 2.50 & 7 \\
\hline Special entrepreneurial project & 0 & 2 & 2 & 6 & 8 & 4.11 & 2 \\
\hline Community service & 4 & 1 & 2 & 8 & 3 & 3.28 & 6 \\
\hline \multirow[b]{2}{*}{ Percentage } & 12 & 15 & 27 & 56 & 34 & & \\
\hline & $8.3 \%$ & $10.4 \%$ & $18.8 \%$ & $38.9 \%$ & $23.6 \%$ & & \\
\hline
\end{tabular}

Table 2. Instructors opinion on the suggested mechanisms to ensure education and research closely to the reality in the society.

\begin{tabular}{|c|c|c|c|c|c|c|c|}
\hline \multirow{2}{*}{ Mechanism } & \multicolumn{5}{|c|}{ Rating (frequency) } & \multirow{2}{*}{ Mean } & \multirow{2}{*}{ Rank } \\
\hline & Never 1 & Rarely 2 & Often 3 & Very often 4 & Always 5 & & \\
\hline Field trips/visits & 3 & 10 & 8 & 12 & 3 & 3.05 & 6 \\
\hline Experiential learning & 6 & 9 & 7 & 8 & 5 & 2.91 & 8 \\
\hline Visiting guest lecturers & 1 & 5 & 9 & 15 & 6 & 3.56 & 2 \\
\hline Student practical attachment & 3 & 7 & 10 & 6 & 10 & 3.36 & 3 \\
\hline Invited speakers from industries and farming community & 1 & 4 & 9 & 10 & 12 & 3.77 & 1 \\
\hline Involvement of stakeholders in curriculum development & 5 & 8 & 9 & 9 & 5 & 3.03 & 7 \\
\hline Special entrepreneurial project & 3 & 4 & 12 & 11 & 5 & 3.31 & 4 \\
\hline Community service & 6 & 5 & 11 & 9 & 5 & 3.06 & 5 \\
\hline \multirow[b]{2}{*}{ Percentage } & 28 & 52 & 75 & 80 & 51 & & \\
\hline & $9.8 \%$ & $18.2 \%$ & $26.2 \%$ & $28.0 \%$ & $17.8 \%$ & & \\
\hline
\end{tabular}

Table 3. Rating of research heads on the mechanisms ensuring education and research closely related to the reality in the society.

\begin{tabular}{|c|c|c|c|c|c|c|c|}
\hline \multirow{2}{*}{ Mechanism } & \multicolumn{5}{|c|}{ Rating (frequency) } & \multirow{2}{*}{ Mean } & \multirow{2}{*}{ Rank } \\
\hline & Never 1 & Rarely 2 & Often 3 & Very often 4 & Always 5 & & \\
\hline Field trips/visits & 0 & 4 & 0 & 6 & 1 & 3.36 & 6 \\
\hline Experience sharing & 1 & 1 & 0 & 7 & 1 & 3.60 & 4 \\
\hline Visiting guest researchers & 0 & 1 & 2 & 4 & 2 & 3.78 & 3 \\
\hline Practical participatory research with stakeholders & 2 & 0 & 4 & 4 & 0 & 3.00 & 7 \\
\hline Invited speakers from industries and farming community & 1 & 1 & 2 & 2 & 5 & 3.82 & 1 \\
\hline $\begin{array}{l}\text { Involvement of stakeholders in determining research } \\
\text { agenda and evaluating research outputs }\end{array}$ & 1 & 1 & 7 & 1 & 0 & 2.80 & 8 \\
\hline Special entrepreneurial project & 0 & 1 & 3 & 3 & 3 & 3.80 & 2 \\
\hline Community service & 1 & 0 & 3 & 3 & 2 & 3.56 & 5 \\
\hline \multirow[t]{2}{*}{ Frequency } & 6 & 9 & 21 & 30 & 14 & & \\
\hline & $7.5 \%$ & $11.25 \%$ & $26.25 \%$ & $37.5 \%$ & $17.5 \%$ & & \\
\hline
\end{tabular}


Table 4. Researchers rating on the suggested mechanisms ensuring education and research closely to the reality in the society.

\begin{tabular}{|c|c|c|c|c|c|c|c|c|}
\hline \multirow{2}{*}{\multicolumn{2}{|c|}{ Mechanism }} & \multicolumn{5}{|c|}{ Rating (frequency) } & \multirow[t]{2}{*}{ Mean } & \multirow[t]{2}{*}{ Rank } \\
\hline & & Never 1 & Rarely 2 & Often 3 & Very often 4 & Always 5 & & \\
\hline \multicolumn{2}{|c|}{ Field trips/visits } & 3 & 4 & 7 & 9 & 2 & 3.12 & 7 \\
\hline \multicolumn{2}{|c|}{ Experience sharing } & 1 & 2 & 4 & 16 & 2 & 3.64 & 4 \\
\hline \multicolumn{2}{|c|}{ Visiting guest researchers } & 0 & 3 & 2 & 12 & 8 & 4.00 & 1 \\
\hline \multicolumn{2}{|c|}{ Practical participatory research with stakeholders } & 0 & 5 & 10 & 8 & 2 & 3.28 & 6 \\
\hline \multicolumn{2}{|c|}{ Invited speakers from industries and farming community } & 2 & 1 & 5 & 11 & 6 & 3.72 & 3 \\
\hline \multicolumn{2}{|c|}{$\begin{array}{l}\text { Involvement of stakeholders in determining research agenda } \\
\text { and evaluating research outputs }\end{array}$} & 0 & 6 & 8 & 6 & 5 & 3.40 & 5 \\
\hline \multicolumn{2}{|c|}{ Special entrepreneurial project } & 1 & 2 & 5 & 9 & 8 & 3.84 & 2 \\
\hline \multicolumn{2}{|c|}{ Community service } & 2 & 3 & 13 & 7 & 0 & 3.00 & 8 \\
\hline \multirow{2}{*}{ Total } & Frequency & 9 & 26 & 54 & 78 & 33 & & \\
\hline & Percentage & $4.5 \%$ & $13 \%$ & $27 \%$ & $39 \%$ & $16.5 \%$ & & \\
\hline
\end{tabular}

and researchers rated "community service” quite differently at the 5th and 8th least and 5th places, respectively.

Students and alumni also rated "inviting speakers from industries and farming community”, "visiting guest lecturers" and "special entrepreneurial project" as first, second, and third important mechanisms, respectively (Tables 5 and 6). Students rated "involvement of stakeholders in curriculum development” least. In different from students, however, alumni supported the importance of stakeholders' involvement in curriculum development and they ranked it at the 4th place among eight suggested mechanisms. On the contrary, students appreciated the relevance of "community service" and rated it 4 th.

Generally all six different respondent groups rated the three suggested mechanisms, namely "inviting speakers from industries and farming community”, "visiting guest lecturers" and "special entrepreneurial project", as the top most important for ensuring training and research closely to the reality in the society. Almost all groups of respondents rated experience sharing low. Although there were differences among different groups of respondents in ranking of other four suggested mechanisms, all groups of respondents also supported the need of the other four mechanisms with rating value of more than three. In the present study, it seemed that mechanisms which are rarely or never employed currently by higher education and research institutions were relatively rated high by the respondents to indicate their deficiency. On the contrary, mechanisms somewhat commonly practiced in the current system were rated low relatively.

There were somewhat differences among the six respondent groups for the level of their agreement with the suggested mechanisms. These differences would be estimated either with the response mean values or with the total proporation of positive and negative responses. Under this case, "often”, "very often” and "always" could be considered as positive responses, while "never" and "rarely" would be taken as negative responses. Based on the proportion of their responses, thus, researchers and university heads agreed most strongly with the suggested mechanisms. On the contrary, instructors and alumni were the least to agree with the importance of the mechanisms indicated above that can potentially relate training and research closely to the reality in the society.

Employer respondents were also asked to suggest areas that need to be included for the improvement of students training to facilitate rural transformation and address farmers' problems. None of the employer respondents rated the areas that need improvement with “strongly disagree". About $89.53 \%$ of the respondents agreed or strongly agreed with the areas listed below in Table 7 that need to be included or improved while training the students. As the mean response indicates all areas suggested by employer respondents for improvement got almost equal total rating value close to "agree”, indicating that all suggested areas are equally important for improvement in higher learning institutes. Though there were no significant differences among areas that need improvement, "relevant technical skills" ranked first, followed by "Innovation and information system" and "relevant technical knowledge" third (Table 7).

Agricultural education and training institutions are conventionally viewed as a means for building human capital, but it is important to recognize that this training also has a vital role in building the capacity of organizations and individuals to transmit and adapt to new applications of existing information, new products and processes, and new organizational cultures and behaviours. 
Table 5. Students opinion on mechanisms linking training and research closely to the reality in the society.

\begin{tabular}{|c|c|c|c|c|c|c|c|}
\hline \multirow{2}{*}{ Mechanism } & \multicolumn{5}{|c|}{ Rating (frequency) } & \multirow{2}{*}{ Mean } & \multirow{2}{*}{ Rank } \\
\hline & Never 1 & Rarely 2 & Often 3 & Very often 4 & Always 5 & & \\
\hline Field trips/visits & 4 & 18 & 22 & 32 & 11 & 3.32 & 6 \\
\hline Experiential learning & 7 & 14 & 23 & 28 & 13 & 3.30 & 7 \\
\hline Visiting guest lecturers & 1 & 6 & 15 & 29 & 34 & 4.05 & 2 \\
\hline Student practical attachment & 8 & 13 & 19 & 24 & 20 & 3.42 & 5 \\
\hline Invited speakers from industries and farming community & 2 & 4 & 19 & 22 & 40 & 4.08 & 1 \\
\hline Involvement of stakeholders in curriculum development & 16 & 9 & 23 & 19 & 17 & 3.14 & 8 \\
\hline Special entrepreneurial project & 2 & 13 & 16 & 20 & 35 & 3.85 & 3 \\
\hline Community service & 9 & 10 & 20 & 19 & 29 & 3.56 & 4 \\
\hline \multirow[b]{2}{*}{ Percentage } & 49 & 87 & 157 & 193 & 199 & & \\
\hline & $7.2 \%$ & $12.7 \%$ & $22.9 \%$ & $28.2 \%$ & $29.1 \%$ & & \\
\hline
\end{tabular}

Table 6. Alumni rating on the mechanisms emplaced to insure education and research closely to the reality in the society.

\begin{tabular}{|c|c|c|c|c|c|c|c|}
\hline \multirow{2}{*}{ Mechanism } & \multicolumn{5}{|c|}{ Rating (frequency) } & \multirow{2}{*}{ Mean } & \multirow{2}{*}{ Rank } \\
\hline & Never 1 & Rarely 2 & Often 3 & Very often 4 & Always 5 & & \\
\hline Field trips/visits & 15 & 21 & 33 & 52 & 6 & 3.10 & 5 \\
\hline Experiential learning & 13 & 36 & 35 & 33 & 8 & 2.90 & 8 \\
\hline Visiting guest lecturers & 4 & 14 & 33 & 63 & 13 & 3.53 & 2 \\
\hline Student practical attachment & 22 & 16 & 41 & 42 & 4 & 2.92 & 7 \\
\hline Invited speakers from industries and farming community & 7 & 21 & 23 & 38 & 37 & 3.61 & 1 \\
\hline Involvement of stakeholders in curriculum development & 21 & 22 & 24 & 37 & 22 & 3.13 & 4 \\
\hline Special entrepreneurial project & 15 & 17 & 30 & 27 & 38 & 3.44 & 3 \\
\hline Community service & 23 & 26 & 27 & 34 & 16 & 2.95 & 6 \\
\hline \multirow[t]{2}{*}{ Frequency } & 120 & 173 & 205 & 326 & 144 & & \\
\hline & $12.40 \%$ & $17.87 \%$ & $21.18 \%$ & $33.68 \%$ & $14.88 \%$ & & \\
\hline
\end{tabular}

Table 7. Employers rating to areas that needs to be included/improved while training the students to make them more effective professionals.

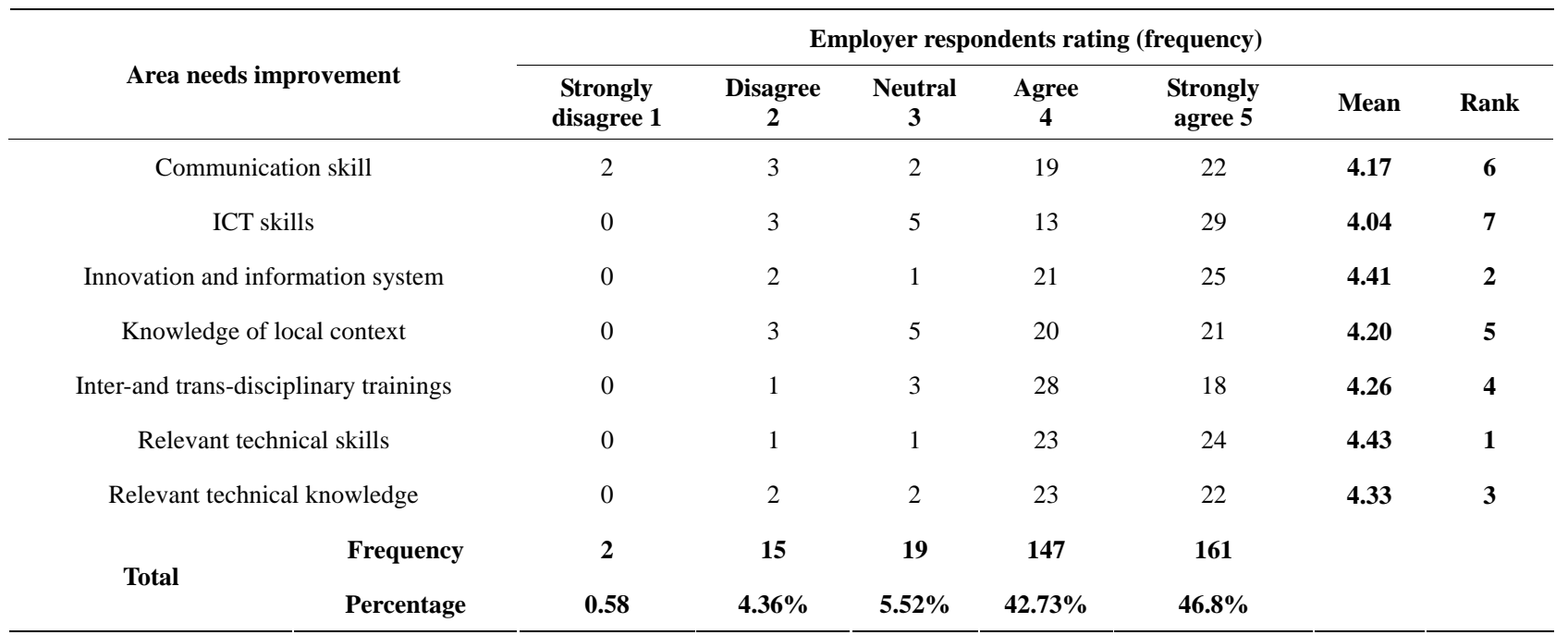


According to Table 7 shown above there appears to be a mind set among the heads of employer organizations in that their fresh graduate employees are lacking some important elements which are important for sensitizing rural transformation and address farmers' problems.

The first most important element that fresh graduates lack was relevant technical skills because of less emphasis on experiential learning on higher education. Therefore, in order to facilitate rural transformation the higher institutions curriculum should be arranged in such a way that the trainees could obtain appropriate technical knowhow. The second missing element was skills related to innovation and information system. So, the training should focus on communication for innovation and information system.

The next important recommendation given by heads of employer organizations as to disciplinary nature of fresh graduates was that the training offered by higher institutions should be of inter-and-trans-disciplinary to enable students to become multidimensional and easily understand the realities of the farmers. This was followed by the recommendation that training programs should be designed in such a way to acquaint the clientele to have relevant technical knowledge in the area that they are going to engage.

The other important recommendations for improving the contribution of graduates were the inclusion of knowledge of local context of the rural people including their livelihood, farming systems, etc. in the curriculum, emphasis on students' improvements of ICT and communication skills.

\section{CONCLUSION AND RECOMMENDATION}

Surveying the appropriateness of the present training programmes of higher education and research institutions to address the actual problems of farmers was explained by suggested mechanisms assessed on university heads, instructors, students, research heads, researchers, and employees (alumni). The suggested mechanisms included field visits/trips, experiential learning, visiting guest lecturers, student practical attachment, invited speakers from industries and farming community, involvement of stakeholders in curriculum development, special entrepreneurial project and community service.

Accordingly, all respondent groups rated "inviting speakers from industries and farming community", "visiting guest lecturers" and "special entrepreneurial project", as the top most important for ensuring training and research closely to the reality in the society. So, the curriculum for the training should give much weight to incorporate these suggested mechanisms.

On the other hand, the first most important element that fresh graduates lack was relevant technical skills because of less emphasis on experiential learning on higher education. Therefore, in order to facilitate rural transformation, the higher institutions curriculum should be arranged in such a way that the trainees could obtain appropriate technical know-how. The second missing element was skills related to innovation and information system. So, the training should focus on communication for innovation and information system.

The other important recommendation given by heads of employer organizations as to disciplinary nature of fresh graduates was that the training offered by higher institutions should be of inter-and-trans-disciplinary to enable students to become multidimensional and easily understand the realities of the farmers.

In addition to this, to improve the contribution of graduates, it was also recommended to include in the curriculum knowledge of local context of the rural people including their livelihood, farming systems, etc., emphasis on students' improvements of Information Communication Technology (ICT) and communication skills.

\section{ACKNOWLEDGEMENTS}

The original research results of this paper are derived by the TRANSACT (Strengthening Rural Transformation Competences of Higher Education and Research Institutions in the Amhara Region, Ethiopia) project. This project is funded by the Austrian Development Agency, the operational unit of the Austrian Development Cooperation (ADC), under the frame of APPEAR (Austrian Partnership Programme in Higher Education \& Research for Development). Hence, the authors sincerely acknowledge APPEAR-TRANSACT project for its support.

\section{REFERENCES}

[1] Engestro, M.Y. (1987) Learning by expanding: An activity-Theoretical approach to developmental research. Orienta-Kunsultit, Helsinki.

[2] Mager, R.F. (1961) On the sequencing of instructional content. Psychological Reports, 9, 405-413.

[3] Illeris, K. (2002) The three dimensions of learning: Contemporary learning theory in the tension field between the cognitive, the emotional and the social. NIACE, Leicester.

[4] Mezirow, J. (1991) Transformative dimensions of adult learning. Jossey-Bass, San Francisco.

[5] BoPED (2002) Bureau of planning and economic development report, in the Amhara regional state. Bahir Dar.

[6] UNECA (United Nations Economic Commission for Africa) (1996) Sustainable agriculture and environmental rehabilitation program (SAERP). Statistical Master book on sectoral conditions and activities, in the Amhara regional state.

[7] Gergen, K.J. (1994) Realities and relationships. Harvard University Press, Cambridge. 


\section{ACRONYMS AND TERMINOLOGIES}

1) Amhara: One of the regions in Ethiopia located in the north western of the country;

2) Gondar: One of the zones in Amhara region located in the north west of it;

3) Bahir Dar: Capital city of Amhara region located in the north western of it;

4) ANRS: Amhara National Regional State;

5) Woreda: District;

6) ARARI: Amhara Region Agricultural Research Institute;
7) Tigray, Oromia, Afar, Benishangul Gumuz: National regional states in Ethiopia;

8) East Gojam, West Gojam, Awi, North Gondar, South Gondar, Wag Himra, North Wollo, South Wollo, North Shewa: Administrative zones in Amhara region;

9) DA: Development Agent (Extension worker working with a farmer at a grass root level);

10) NGO: Non Governmental Organization;

11) ICT: Information Communication Technology;

12) UNDP: United Nations Development Program. 